\title{
From Ghanaian Folk Song to Contemporary Art Music for $B^{b}$ Atenteben and Piano
}

\author{
Mawuyram Quessie Adjahoe \\ Department of Music and Dance, Faculty of Arts, \\ College of Humanities and Legal Studies \\ University of Cape Coast, Cape Coast, Ghana \\ e-mail: madjahoe@ucc.edu.gh, adjayram@yahoo.com
}

Published online: 30 December 2017

Cite this article (APA): Adjahoe, M.Q. (2017). From Ghanaian folk song to contemporary art music for $\mathrm{B}^{\mathrm{b}}$ atenteben and piano. Malaysian Music Journal, 6 (2), 94-114.

\begin{abstract}
In recent decades, many Ghanaian composers have incorporated traditional Ghanaian folk tunes into their western-influenced compositional works. Among them are Ephraim Amu, Joseph Hanson Kwabena Nketia, Nicholas Nichodemus Kofie, and Cosmas Worlanyo Kofi Mereku who used folk tunes as themes for extended musical compositions. These compositions represent the hybrid cultural identity of Ghanaian composers whose roots are entrenched in traditional and Western musical cultures. This article focuses on the compositional technique $\mathrm{I}$, as a modern composer, utilised in integrating the musical elements and features of 'Nyavs Nyee Tu Gbomedodoe', a Ghanaian folk song into a new contemporary art music composition for the $\mathrm{B}^{\mathrm{b}}$ atcnteben (a modified traditional bamboo flute) and piano. In this new composition also titled Nyavs Nyee Tu Gbomedodoe, I extended beyond the standard tuning systems of the modified $\mathrm{B}^{\mathrm{b}}$ atcnteben by structuring the piece based on sonata form. The sonata form contains modulation from the tonic triggering me to include two new chromatic pitches, expanding the capabilities of the modified $\mathrm{B}^{\mathrm{b}}$ atcnteben. In this article, I argue for new possibilities of atcnteben 'neoclassical' compositions by combining compositional techniques from western classical and Ghanaian traditional music.
\end{abstract}

Keywords: Ghanaian folk songs, Nyav Nyee Tu Gbomedodoe, $\mathrm{B}^{\mathrm{b}}$ atcnteben. 


\section{Introduction}

In modern Ghana, the study and performance of musical instruments is a core subject in some of the music programmes in secondary and tertiary institutions. These programmes require the students to perform music composed for African/Ghanaian traditional musical instruments as well as western musical instruments. The $\mathrm{B}^{\mathrm{b}}$ atenteben is also studied and performed for practical examinations in the institutions. Atenteben is the traditional bamboo flute of the people of Kwahu in the Eastern Region of Ghana, which, initially had three or four pitch-holes and was held transversely like the western flute. Most of these pieces arranged for the $\mathrm{B}^{\mathrm{b}}$ atcntebsn are combined with piano accompaniment.

According to Flolu and Amuah (2003), the study of music (western music) began in the then Gold Coast (now Ghana) during the period of the Mission Schools in the 1880s to train local workers to teach hymn singing in the churches. In the 1950s, the mission schools' music programme taught the students music theory up to the level of the Associated Board of the Royal Schools of Music (ABRSM Grade V and VII). Ward (1939), a British music educator and historian, wrote:

African music and European music will certainly influence each other in the future. Gold Coast teachers can do African music a great service by studying it, understanding it, teaching it; and by knowing European music well enough to see what help the two can give each other. A European can give Africans no help in the study of African music; but he may be able to help them to understand and enjoy better music of his own race (Ward, 1939, xii, cited in Flolu and Amuah, 2003, p. 12).

The usage of folk songs as themes for large musical works has been a common practice for centuries. Kerman (1980) and Forney and Machlis (2007) among others, stated that for several centuries, many composers have realised that folk songs provided rich inspirational resources for compositions. Again, Forney and Machlis, asserted that,

The interest in folklore and the rising tide of nationalism inspired Romantic composers to make increased use of the folk songs and dances from their native lands. As a result, a number of national idioms-Hungarian, Polish, Russian, Bohemian, Scandinavian, and eventually American-flourished, greatly enriching the melodic, harmonic, and rhythmic language of music. (Forney and Machlis, 2007, p. 234)

The style and elements (melodic, rhythmic and harmonic structures as well as textual contour) of Ghanaian folk songs were recognised as compositional materials for art music very early in Ghana in the 1920s (Agordoh, 2002, p. 140). Agordoh again records that Ephraim Amu (1899-1995) uniquely advanced the integration of indigenous music in church worship in the Presbyterian and the Evangelical Presbyterian Churches in Ghana by creating the consciousness of the artistic potential of the tonal inflection and rhythmic flow of both the Akwapem 
Twi and Ewe languages. Agordoh emphasised that this trend is observable in Amu's compositions including Hadzidzi Ame Fe Gbogbo and Agbexoxo mo (p. 144). Agordoh added that other composers such as Isaac Daniel Riverson (1901-1967), Joseph Hanson Kwabena Nketia (b. 1921), Michael Kofi Amissah (1923-2010) and many others wrote anthems in their various languages "in the style of traditional tunes for churches and concerts in schools" (Agordoh, 2002, pp. 149-162).

While western music was taught in mission schools, the study of traditional African/Ghanaian music was neglected in the school system then. The imposition of western music and culture into the education system soon created dissatisfaction among many Ghanaian citizens. Consequently, the music curriculum in the Mission Schools of Ghana was re-evaluated in 1924 (Flolu and Amuah, 2003, p.12). Forsythe (1940) wrote:

African children should be taught African music alongside European music. Only in this way can we expect to create an African school of composition, which will necessarily have to be a fusion of African and European idioms. Of course all this rests with individual genius, but (we) look forward to the day when great works by African composers, works stamped with that originality and depth that is African's will be heard in concert halls of the world (1940, pp. 174-75, cited in Flolu and Amuah, 2003, pp. 12-13).

Ghanaian music composers have been developed since Ephraim Amu's era in 1926 when he was teaching at Akropong (Agordoh, 2002, p. 146). Agordoh again provides a comprehensive list of pioneer composers who had included traditional musical elements into art songs as follows: Ephraim Amu, Joseph Hanson Kwabena Nketia, Nicholas Zinzendorf Nayo, Alfred Entsua-Mensah, Otto Boateng, Samuel George Boateng, Frank Kofi Nyaku, Atta Annan Mensah, Charles Graves, Ernest Safo, Joseph Michael Teye Dosso, Joseph Samuel Maison, Robert George Kodzo Ndo, Michael Kofi Amissah, Isaac Daniel Riverson, Francis Onwona Safo, Adolphus Ato Robertson Turkson, Walter Komla Blege, and Kenn Kafui (pp. 146-166).

\section{The Traditional and Modified Atenteben}

In Ghana, the traditional atenteben was used to accompany singing, drumming, dancing and to mourn the dead. According to oral history, there is no accurate fact record about the origin of the atentebsn, but it became famous among the people of Kwahu after one man named Akwasi Fori was found playing the instrument to mourn his dead uncle. Akwasi Fori continued to play a particular tune for three days at the bank of a river and drowned himself afterwards. This tune is named 'Akwasi Fori' after the first performer. Although it exists in variety of versions, it is heard especially among the Akan-speaking people of Ghana to announce and mourn the dead. Figure 1 shows a photo of Ephraim Amu playing the traditional atenteben. 


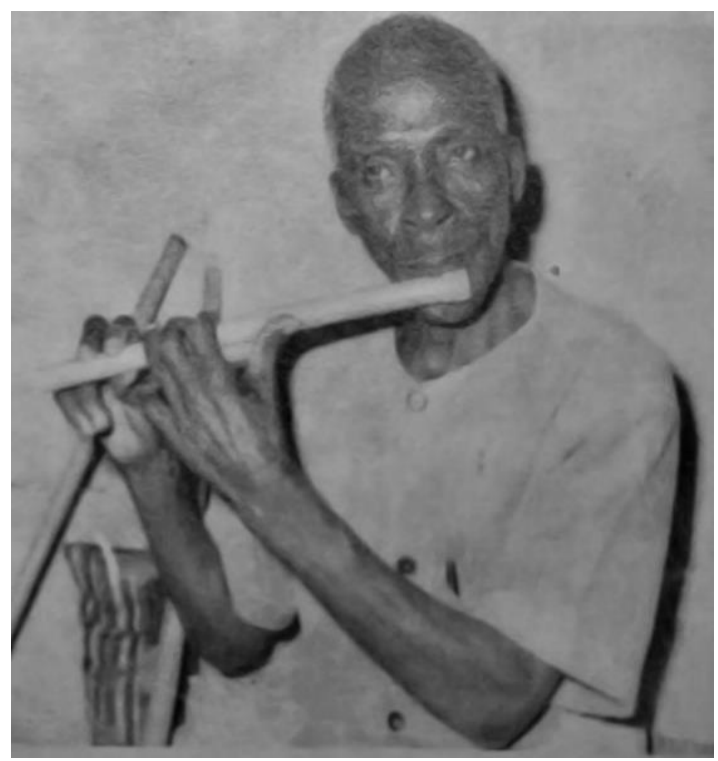

Figure 1. Photograph of Ephraim Amu playing the traditional atcntebcn. (Source: Agyemang, 1988, p. 65)

The traditional version of the atcnteben with three pitch-holes produced four pitches while the four pitch-holes atcnteben created five pitches. This is confirmed by Agyemang (1988) who stated that in 1926-27, Ephraim Amu, a Ghanaian composer found that "the Kwahu flute could not produce all the notes of the scale played on the Ewe and other Akan ethnic flutes" (p. 79). The ranges and scales of the traditional three pitch-holes as well as the four pitch-holes atcnteben can be found in Figures 2 and 3 respectively.

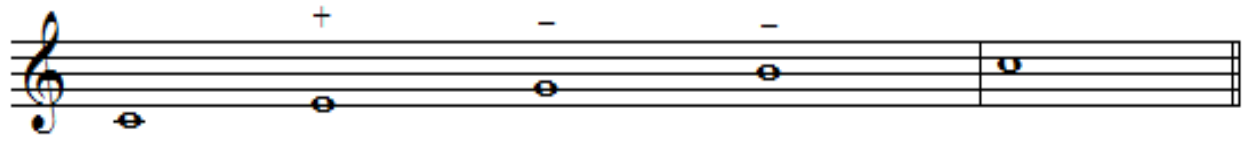

Figure 2. The range and scale of the three pitch-holes traditional atcnteben.

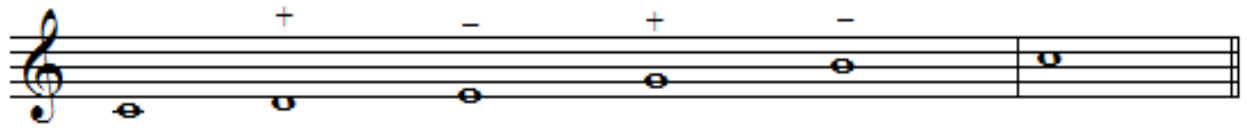

Figure 3. The range and scale of the four pitch-holes traditional atcnteben.

Amu was the first composer who first introduced the music of Ghana into the national music programme. He combined western music with African drumming and piping into the musical activities at the Presbyterian Teachers 
Training College (now Presbyterian College of Education) at Akropong and Achimota School at Accra where he taught from the years 1926-1933 and 19341937 respectively (Flolu and Amuah, 2003, pp. 6-13).

The music programmes at national schools encountered difficulty in arranging music for traditional atenteben tuned to its own unique system of four and five pitch scales with western musical instruments adjusted to equal temperament. After examining the organology and tuning system of the traditional atcnteben, Amu decided to develop a new atcnteben, which would enable his students to play songs composed in Western diatonic scale. Amu sought permission from the Asante King Otumfuo Nana Sir Osei Agyeman Prempeh II to learn how to manufacture and play the atcnteben. The Asante King allowed Amu to be taught by his (the King's) master flautist and maker Opanyin Kofi Poku (Agyemang, 1988, p. 79). Although progress was slow because every initial success came with its own challenges, Amu succeeded by increasing the number of pitch-holes to seven thereby increasing the number of possible pitches of the atcnteben (Figure 4).

Today, Amu's modified atenteben has seven pitch-holes tuned in $\mathrm{B}^{\mathrm{b}}, \mathrm{C}$ and $\mathrm{D}$ major to western standard equal temperament. Unlike the traditional atcnteben which is held diagonally (Figure 1), the modified atenteben is played vertically (Figure 4). Amu emphasised in an interview that the most common atenteben in Ghanaian schools, colleges and universities is the atcnteben in $\mathrm{B}^{\mathrm{b}}$ (Adjahoe, 1987, pp. 8-12) (Figure 5).

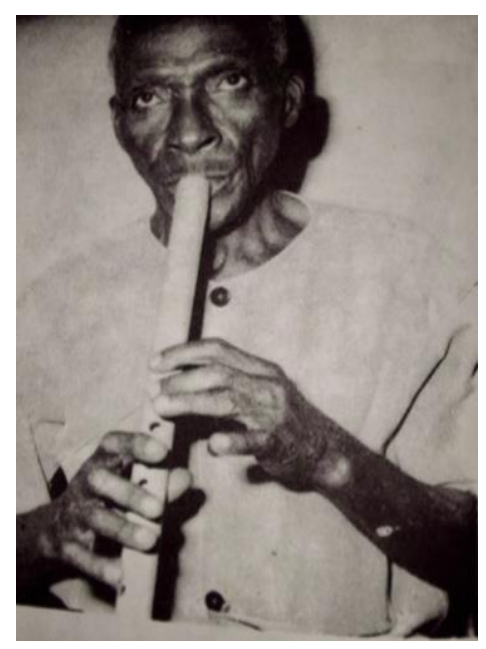

Figure 4. Amu plays his newly developed/modified atcntebcn. (Source: Agyemang, 1988, p. 66) 

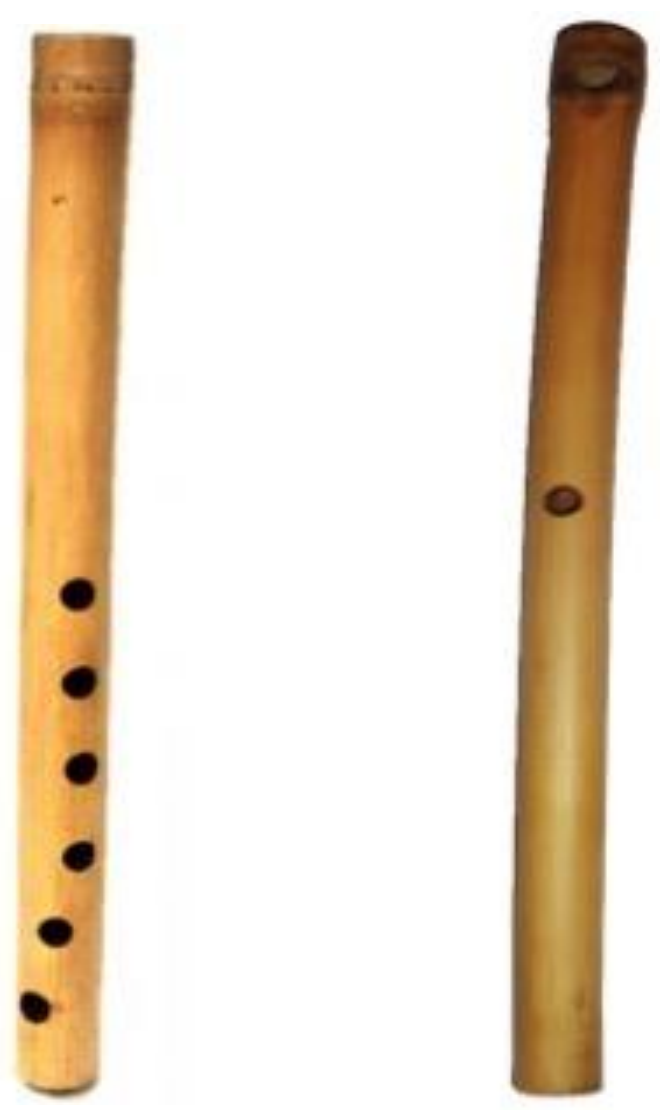

Figure 5. A photograph of the front and back views of modern $\mathrm{B}^{\mathrm{b}}$ atenteben used in Ghanaian schools, colleges and universities. (Source: Adjahoe, 2016a, p.1)

Due to its mode of manufacturing, the atenteben could only play music written in its 'natural' key (the key in which it is tuned). Today, (2017), there are a number of works by African/Ghanaian composers for the $\mathrm{B}^{\mathrm{b}}$ atenteben in $\mathrm{B}^{\mathrm{b}}$ major using its 'natural' scale. However, Amu suggests that in order to expand beyond this limitation, music for the $\mathrm{B}^{\mathrm{b}}$ atenteben should be written in the key of $\mathrm{C}$ major. He said: "... music for the $\mathrm{B}^{\mathrm{b}}$ atenteben must be written in the key of $\mathrm{C}$ major, this way, the Ghanaian traditional bamboo flute would also be considered a transposing musical instrument like the trumpet in $\mathrm{B}^{\mathrm{b}}$ " (Adjahoe, 1987, p. 13). Amu and his students wrote music for this instrument in the transposed key of $\mathrm{C}$ major using only the diatonic pitch, which became the model for other composers. So, in Ghana, most composers compose music for the atcnteben using the western diatonic pitches in the key of $\mathrm{C}$ major (Figure 6). 


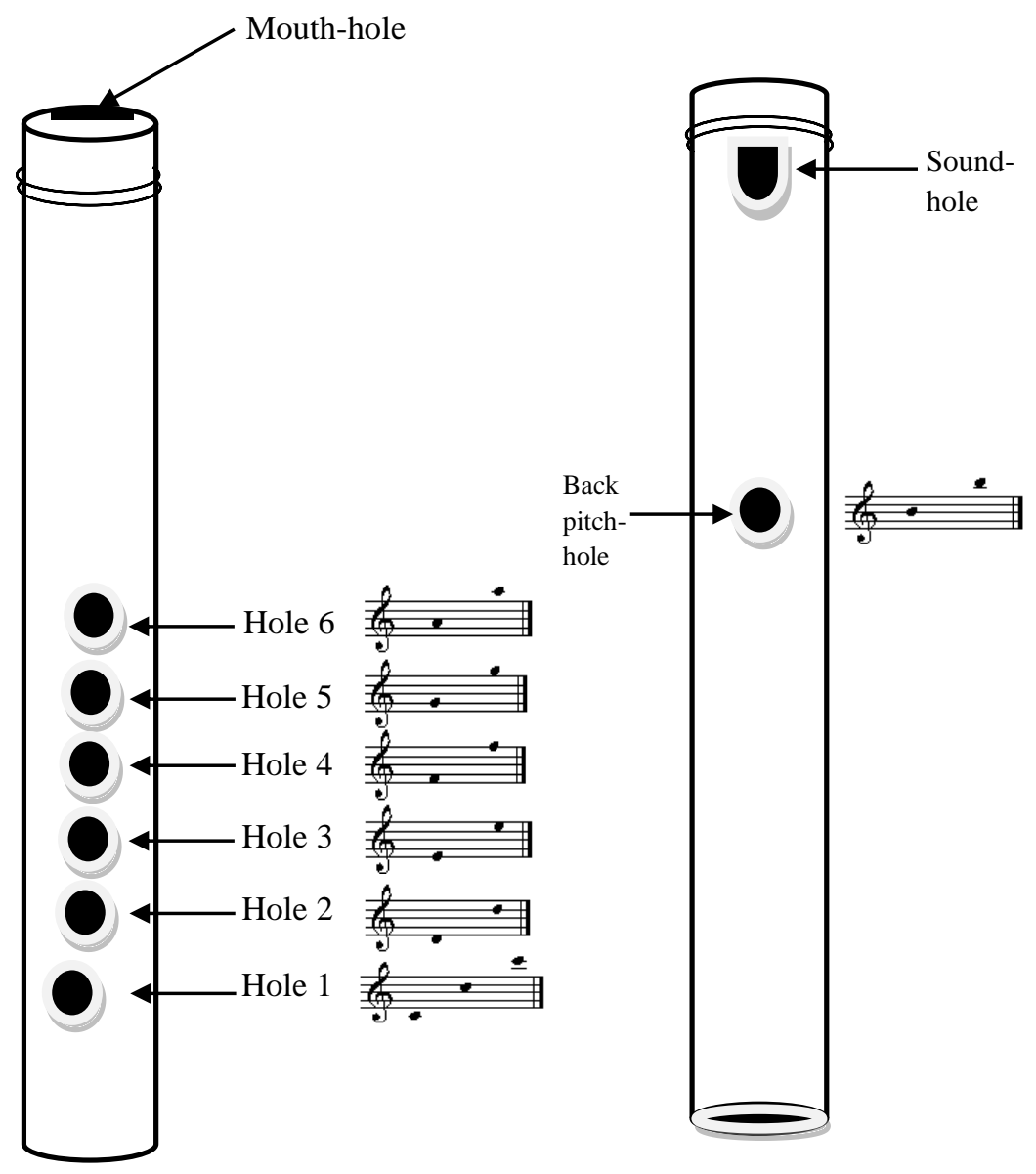

Figure 6. An illustration of the diatonic western musical notes capable of being produced on the $\mathrm{B}^{\mathrm{b}}$ atenteben using the key of $\mathrm{C}$ major. (Source: Adjahoe, 2016a, p.3)

In an attempt to increase the possibilities of pitch production in the musical instrument, Nana Danso Abiam composed music that explored the use of two additional chromatic notes for the $\mathrm{B}^{\mathrm{b}}$ atenteben (Craig Harris, 2017); F\#4 and $\mathrm{B}^{\mathrm{b}} 4$ (Adjahoe, 2016a, pp. 15-20). The Pan-African Orchestra (PAO) formed by Nana in 1988 travelled across Africa to perform music compositions for the modified

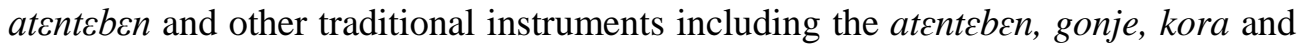
gyile. His mission with the PAO, originally a 30-piece ensemble, had been to explore the classical foundations of traditional African music and to cultivate an integrated continental art form through new compositional and orchestral techniques (Appiah, 2015).

Through examining several experimentations on alternative fingering techniques by Nana Danso Abiam, Togbe Kodzo Amu (Ephraim Amu's youngest son) I have discovered that the instrument can perfectly play music written in the following keys: C major, F major, G major, A minor and the Aeolian modes of C, F 
and $\mathrm{G}$ (Adjahoe, 2016a, p. 28). As a composer, performer, instructor of piano and a number of Ghanaian traditional instruments - notably the $\mathrm{B}^{\mathrm{b}}$ atcntebcn, Ghanaian traditional drums and gyile-I have been composing music for my students using varieties of themes. These themes may be self-composed or inspired from Ghanaian folk songs.

The aim of this article is to demonstrate that music for the $\mathrm{B}^{\mathrm{b}}$ atcnteben can be composed in various other keys than the 'natural' key of the instrument. I present 1) the compositional technique I utilised in integrating the musical elements of 'Nyavo Nyee Tu Gbomedodoe', a Ghanaian folk song, into a new contemporary art piece; and 2) the development of a hybrid composition that represents my identity as a modern Ghanaian composer with roots in Ghanaian traditional culture and western influenced musical heritage. I present new experiences in composing music for the $\mathrm{B}^{\mathrm{b}}$ atenteben through my composition titled a Nyavs Nyee Tu Gbomedodoe, a contemporary art music for $\mathrm{B}^{\mathrm{b}}$ atcnteben and piano. I also highlight the musical features of Ghanaian folk songs and 'Nyavo Nyee Tu Gbomedodoe'. I discuss the inspiration for this new composition and explore composition techniques for the $\mathrm{B}^{\mathrm{b}}$ atcnteben.

\section{Inspiration to Compose Art Music based on Ghanaian Folk Songs}

I attended Peki Secondary School (now Peki Senior High Secondary School) between 1974 and 1979 in Peki Avetile. During this period, Ephraim Amu was also living in Peki Avetile, his home-town, as a retired music teacher, composer and educator. I became attracted to Ephraim Amu's music through his youngest son, Togbe Kodzo Amu, who was always playing music on the atcnteben, while I accompanied him on his father's grand piano. Togbe Kodzo Amu and I most often performed his father's compositions. As we performed the music, I realised that Ephraim Amu integrated the musical themes and features of Ghanaian folk songs in his musical compositions. Consequently, I developed interest in the folk songs of my ancestral tribe, Ewe.

Later, in my career as composer, I was motivated further by Ralph Vaughan Williams (1872-1958) who stated that "The art of music above all other arts is the expression of the soul of a nation. The composer must love the tunes of his country and they must become an integral part of him" (Forney and Machlis, 2007, p. 357). I am also enthused by Béla Bartók’s (1881-1945) quotation:

What is the best way for a composer to reap the full benefits of his studies in peasant music? It is to assimilate the idiom of peasant music so completely that he is able to forget all about it and use it as his musical mother tongue. (Forney and Machlis, 2007, p. 359)

I employed Ewe and other Ghanaian folk songs as themes to write contemporary art music for the following genres: $\mathrm{B}^{\mathrm{b}}$ atcnteben and piano, voice and piano, $\mathrm{B}^{\mathrm{b}}$ atcnteben trios, and quartets and piano solo. The discussion of my art music Nyavo Nyee Tu Gbomedodoe as an expression of my style stems from Apel's (1997) declaration that, 
In a musical composition, 'style' refers to the methods of treating all the elements-form, melody, rhythm, etc. In practice, the term may be applied to single works (e.g., the style of Tristan compared to that of Die Meistersinger); to composers (the style of Wagner compared to that of Beethoven); to types of composition (operatic style, symphonic style, motet style, church style); to media (instrumental style, vocal style, keyboard style); to methods of composition (contrapuntal style, homophonic style, monodic style); to nations (French style, German style); to periods (baroque style, romantic style); etc. Also, such terms are sometimes used in combination, e.g., 'Beethoven's symphonic style,' 'German romantic style,' 'instrumental style of the baroque,' etc (pp. 811-812).

Thus, I present the compositional techniques I have utilised including espousing the musical elements of 'Nyavs Nyee Tu Gbomedodoe' to articulate and expound my own creative compositional technique of a contemporised version of Nyavs Nyee Tu Gbomedodoe for $\mathrm{B}^{\mathrm{b}}$ atcnteben and piano. In this art music NyavNyee Tu Gbomedodoe I have demonstrated Béla Bartók's assertion by assimilating the idiom of the folk tune. I have completely forgotten all about it through the musical creative processes expressed in the work. This means I have used the folk song as my musical mother tongue to illustrate my roots in Ghanaian traditional music, which has been influenced by Western musical culture.

The tendency of incorporating traditional elements in new music is still ongoing in today's Ghana. We can mention names such as Cosmas Worlanyo Kofi Mereku, and Nicholas Nichodemus Kofie who incorporated traditional musical elements in their contemporary art songs. Young Ghanaian composers were taught by the older ones at one time or the other. For example, I was taught by Adolphus Ato RobertsonTurkson during my years as an undergraduate. I remember submitting my early compositions to Ephraim Amu to vet when I visited Peki Avetile in the holidays. I was also fortunate to be trained by Michael Kofi Amissah when I was pursuing my Master of Philosophy in Music Theory and Composition. Then also, Cosmas Worlanyo Kofi Mereku was the principal supervisor for my doctoral thesis.

\section{Ghanaian Traditional Music and Folk Songs}

Apel (1997) asserts that folk song is the category of music that is found among rural communities. He continues to say that this type of music is distinctly opposed to art music, which is the work of musically trained composers (p. 323). In addition Nketia says,

Ghanaian traditional music is the music of traditional institutions, which were developed, in the pre-colonial period. It represents the artistic expression of Ghanaians in response to the needs and pressures of their own environment.

Examples of this music are work songs (such as those sung by fishermen, craftsmen and farmers), funeral dirges, lullabies, and the music that accompanies the celebration of such rites as circumcision, puberty and marriage. This music is 
predominantly vocal, and its texts reflect the socio-cultural circumstances in which it is functional. (Nketia, 1978, p.1; cited in Agawu, 1984, p. 38)

Nketia's description of Ghanaian traditional music rightly demonstrates the various songs that can be classified as traditional or folk songs. 'Nyavs Nyee Tu Gbomedodoe', the folk song used for this art music was developed in the precolonial period and has not been acculturated by western musical elements. It is vocal, and its texts "reflect the socio-cultural circumstances in which it is functional" (Nketia, 1978, cited in Agawu, 1984, p. 1).

\section{Musical Features of Ghanaian Folk Songs}

Ghanaian folk songs are usually short due to their functions as vehicles of communal expression for joy, grief, entertainment, correction of bad behaviour, initiation of rites, worship, rituals, work and detest of wicked as well as authoritative rulers (Nketia, 1974, pp. 21-24; Agordoh, 2002, p. 28; Younge, 2011, p. 36). As vehicles of communal expression of various emotions, the Ghanaian folk song is structured in what is commonly known as 'call-and-response' and 'cantorand-chorus' forms. These musical forms permit a leader to introduce the music while the community provides the response or the chorus (Nketia, 1974, pp. 189205; Younge, 2011, p. 36). Consequently, Ghanaian folk songs have very few texts that convey the paramount or the intended messages (Nketia, 1974, pp. 189-205; Younge, 2011, p. 190). Very often, Ghanaian folk songs have one tonality in tetratonic, pentatonic, hexatonic, septatonic modes (Nketia, 1974, pp. 116-124). Tonal inflections play a significant role in expressing the meaning of the text in Ghanaian folk songs. Hence, the melodies are constructed to mirror the tonal inflections of the language of the society (Nketia, 1974, pp. 186-188; Agawu, 1984, p. 39; 1988, pp. 127-144). Ghanaian folk songs have repetitive patterns found either in the melody or rhythmic organisation (Nketia, 1974, pp. 168-174, pp. 180-188).

The characteristics enumerated above can be said of the folk song 'Nyavo Nyee Tu Gbomedodoe'. I have also illustrated how I incorporated these traits in the art music. The detailed analysis of this folk song and the art music can be found below.

\section{'Nyavo Nyee Tu Gbomedodoe' (Folk song)}

From a personal experience, 'Nyavo Nyee Tu Gbomedodoe' is one of the favourite songs of the egbanegba dance of the Ewe of Ghana is. The egbanegba dance is performed by women but accompanied with three drums and two bells by men. The master-drum is known locally as Ouga which means 'big drum'. It is supported by asivui 'hand-drum' and vuvi 'little drum'. As a recreational dance, the egbanegba dance was performed on Sundays after the week's farming activities. The Egbanegba Dance Ensemble of Peki Avetile in the Volta region of Ghana was vibrant in the 1980s and 1990s because the ensemble was always performing during regional and national ceremonies. Today, the troupe performs only at the funeral of a member. The Ewe people or Eweawo as they locally call themselves are one of the major tribes of Ghana. They occupy a very vast stretch of land in the 
southeastern corridor of Ghana sharing a border with the people of the Republic of Togo.

The title of the folk song, 'Nyavs Nyee Tu Gbomedodoe' literally means 'the derogatory remark about me has already been heard in the community'. This is a typical folk song that functions as a vehicle for the expression of grief in the society. It was composed as a result of the circulation of falsehood about one man who found himself defenseless in the community. Although it is difficult to trace the year in which the incident happened, it is understood from the text that the man actually resorted to singing the music as a means of consoling himself and to ask the community to sympathize with him (Esi Amewu, personal communication, 1990). 'Nyavo Nyee Tu Gbomedodoe' is in 'call-and-response' form; and it is in a septatonic mode that includes two pitches of the seventh note (Figure 7).

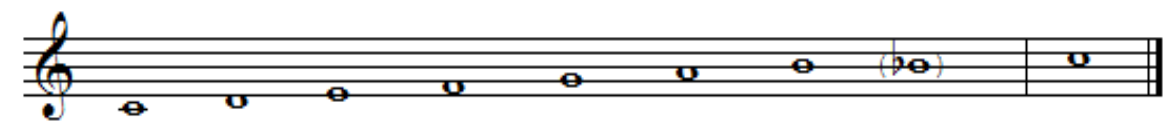

Figure 7. The septatonic mode of the folk song 'Nyavo Nyee Tu Gbomedodoe'. (Source: Adjahoe, 2017)

In the transcription (Figure 8), the text of the 'call' (measures 1-6) reveals the main message and invites the community to participate in the performance. This way, the community would share in the sentiments of the member. A variation on the 'call' (measures 9-10) built on the main concept - the derogatory remarkinvites the community to respond once more. 'Nyavs Nyee Tu Gbomedodoe' also has its melody constructed to mirror the tonal inflections of the society like other Ghanaian folk songs. It has very few words to facilitate communal participation and therefore, appropriate for many repetitions. I have witnessed the performance of this song by the Egbanegba Dance Ensemble of Peki Avetile in the 1990s. The music was sung approximately fifteen times. 


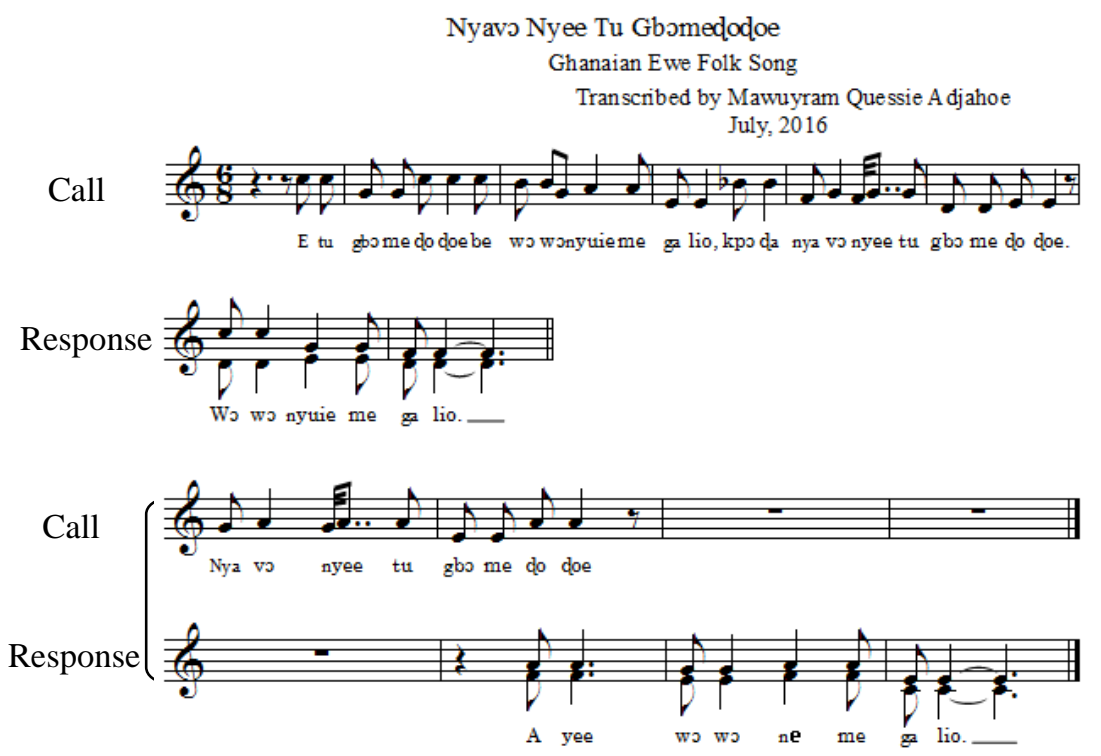

Figure 8. Transcription of the folk song 'Nyavs Nyee Tu Gbomedodoe'.

The texts of the folk song in Ewe and its translation in English are presented below:

\section{Text in Ewe}

\section{Call:}

Etu gbomedodoe;

Be wowonyuie megalio

Kpoda! Nyav-nyee tu

gbomedodoe

\section{Response:}

Wowonyuie megali o

\section{Call:}

Nyav-nyee tu gbomedodoe

\section{Response:}

Ayee!! Wowonyuie megali o

\section{Text in English}

\section{Call:}

The community has heard the derogatory remark;

No need to behave well

Look! My derogatory remark has reached the community

\section{Response:}

No need to behave well

\section{Call:}

My derogatory remark has reached the community

\section{Response:}

'Ayee!!' No need to behave well

This folk song can be analysed in two sections. Each section includes a 'call' and a 'response'. I have used these features in the art-music; so, I will refer to them as 'first call', 'first response' or 'second call' and 'second response'. 
Table 1

Illustration of the structure of the art-music Nyavo Nyee Tu Gbomedodoe

\begin{tabular}{|c|c|c|c|c|c|c|c|c|}
\hline \multicolumn{9}{|c|}{ Piano Introduction } \\
\hline \multicolumn{4}{|c|}{ Theme } & \multicolumn{2}{|c|}{ Tonality } & \multicolumn{3}{|c|}{ Measures } \\
\hline \multicolumn{4}{|c|}{ Built on the second 'call' of the folk song } & \multicolumn{2}{|c|}{$\mathrm{C}$ major } & \multicolumn{3}{|c|}{$1-2$} \\
\hline \multicolumn{9}{|c|}{ Exposition } \\
\hline & First Theme & \multicolumn{2}{|c|}{ Bridge Passage } & \multicolumn{3}{|c|}{ Second Theme } & \multicolumn{2}{|c|}{ Retransition $^{1}$} \\
\hline Tonality & $\mathrm{C}$ major & \multicolumn{2}{|c|}{$\mathrm{C}$ major } & \multicolumn{3}{|c|}{$\begin{array}{c}\text { F major } \\
\text { (Ending with a brief } \\
\text { return to } \mathrm{C} \text { major) }\end{array}$} & \multicolumn{2}{|r|}{ F major } \\
\hline Measures & $3-36 a$ & \multicolumn{2}{|c|}{$36 b-38$} & \multicolumn{3}{|c|}{$39-46$} & \multicolumn{2}{|r|}{$47-50$} \\
\hline \multicolumn{9}{|c|}{ Development } \\
\hline & & \multicolumn{4}{|c|}{ Second Theme } & \multicolumn{3}{|c|}{ Retransition $^{2}$} \\
\hline \multicolumn{2}{|l|}{ Tonality } & \multicolumn{4}{|c|}{ F major } & \multicolumn{3}{|c|}{$\mathrm{C}$ major } \\
\hline \multicolumn{2}{|l|}{ Measures } & \multicolumn{4}{|c|}{$51-68$} & \multicolumn{3}{|c|}{$69-72$} \\
\hline \multicolumn{9}{|c|}{ Recapitulation } \\
\hline & \multicolumn{2}{|c|}{$\begin{array}{c}\text { Second Theme } \\
\text { (And new musical idea) }\end{array}$} & \multicolumn{2}{|c|}{ Retransition $^{3}$} & \multicolumn{3}{|c|}{$\begin{array}{c}\text { First Theme } \\
\text { (Without repeat) }\end{array}$} & Coda \\
\hline Tonality & \multicolumn{2}{|c|}{$\begin{array}{c}\mathrm{C} \text { major (Brief } \\
\text { modulation to } \mathrm{G} \text { major) }\end{array}$} & \multicolumn{2}{|c|}{$\mathrm{C}$ major } & \multicolumn{3}{|c|}{$\mathrm{C}$ major } & $\mathrm{C}$ major \\
\hline Measures & \multicolumn{2}{|c|}{$73-100$} & \multicolumn{2}{|c|}{$101-102 a$} & \multicolumn{3}{|c|}{$102 b-119$} & $120-121$ \\
\hline
\end{tabular}

I have written the art music Nyavs Nyee Tu Gbomedodoe in a modified sonata form (Table 1) with a two-measure first theme (Figure 9).

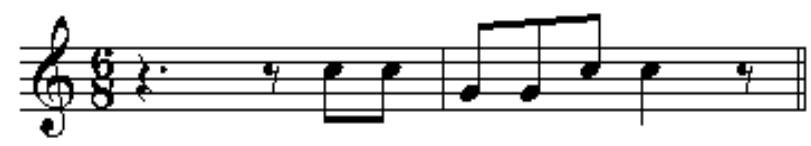

Figure 9. The first theme of the art music.

Structurally, the theme of the art music is taken from the 'first call' or the beginning statement of the folk song. The reason is that, I want the traditional society to identify the folk song in the art-music. Then, by creative design, Nyavo Nyee Tu Gbomedodoe begins with a three-measure piano introduction built on the 'second call' of the folk song and modified at the end to pave way for the statement of the theme in the $\mathrm{B}^{\mathrm{b}}$ atcntebsn (Figure 10). 


\section{Nyavõ Nyee Tu Gbomedodoe}

\section{MAWUYRAM QUESSIE ADJAHOE}

Atenteben in Bb

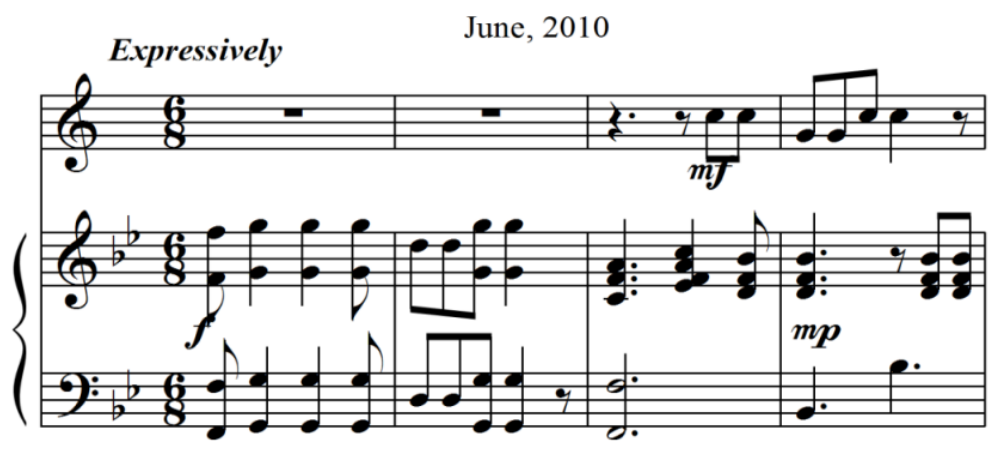

Figure 10. The three-measure piano introduction of the art-music Nyavs Nyee Tu Gbomedodoe, built on the 'second call' in the folk song.

The rhythmic structure of the theme has been used extensively in shaping the melodic pattern of both the $\mathrm{B}^{\mathrm{b}}$ atenteben and the piano. For example, the piano introduction is immediately followed by melodic extensions shaped on the rhythmic model of the theme and created as dialogue between the $\mathrm{B}^{\mathrm{b}}$ atcnteben and the piano (Figure 11).
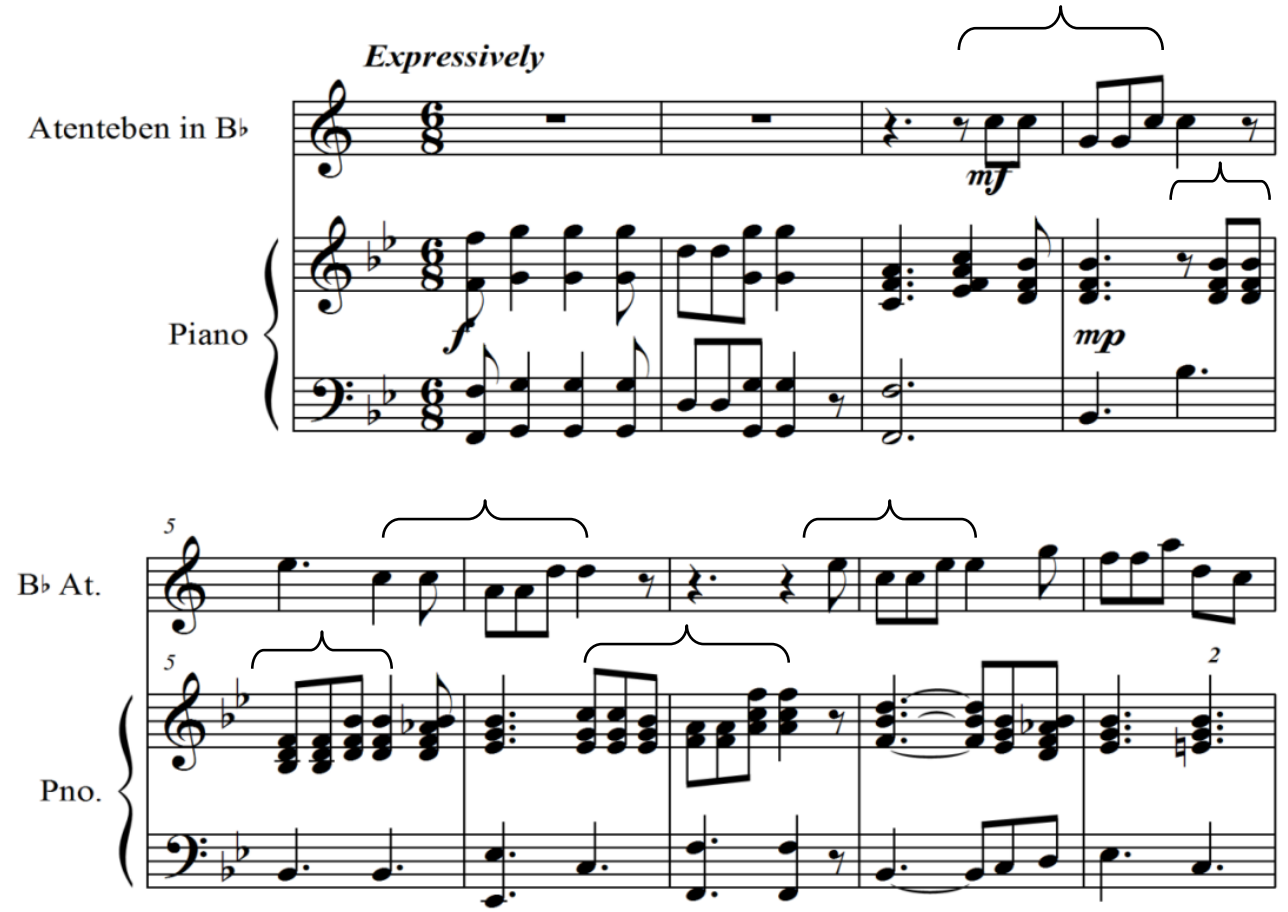

Figure 11. Melodic extensions shaped on the rhythmic model of the theme as dialogue between the $\mathrm{B}^{\mathrm{b}}$ atenteben and the piano. 
The beginning section of the art music is further lengthened by introducing another melodic/rhythmic structure of the folk song; this time, it is the 'first response' in measures 11-16. With a variation, the sample is prolonged and repeated. The piano accompaniment is designed on the rhythmic pattern of the second measure of the main theme (Figure 12).
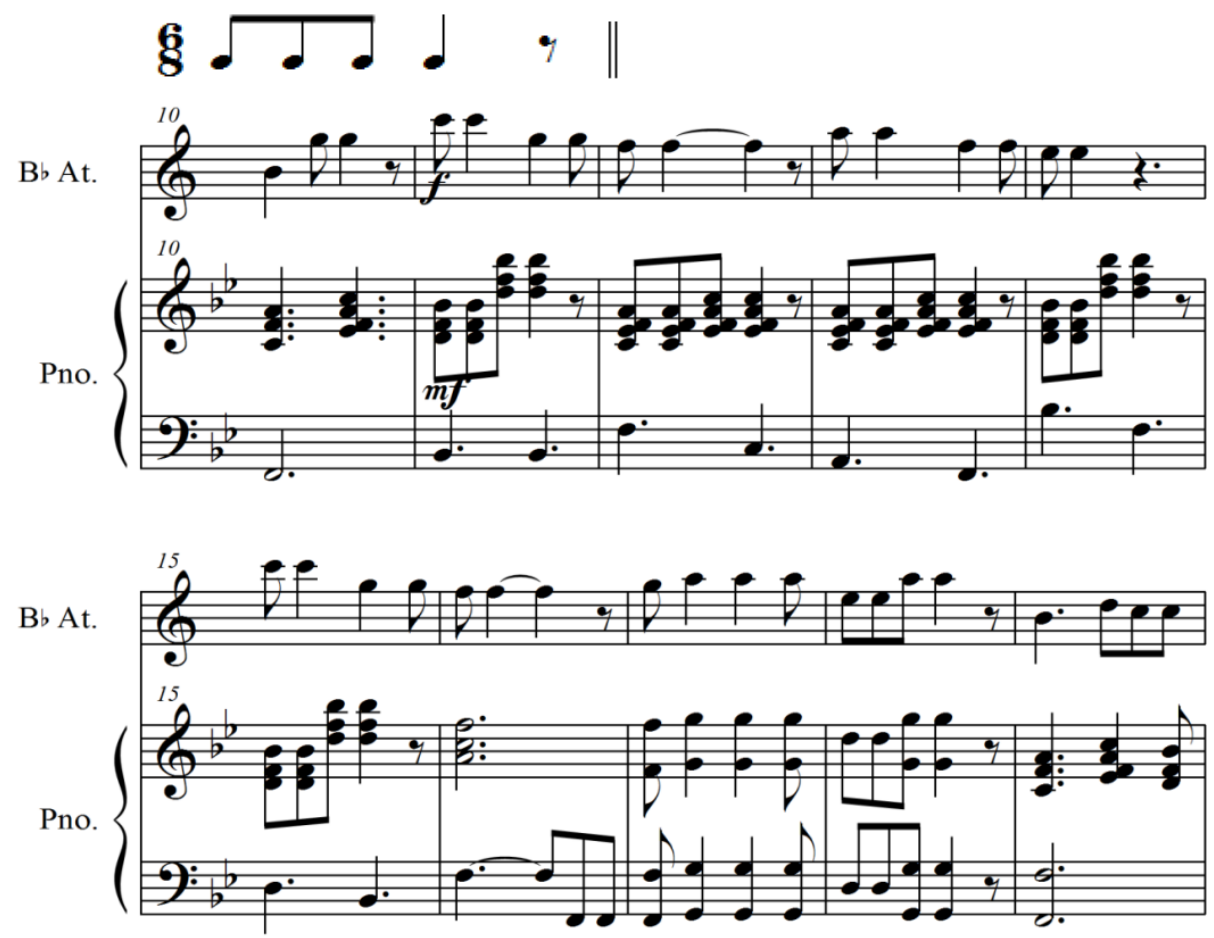

Figure 12. The introduction of the melodic/rhythmic structure of the 'first response' in Nyavs Nyee Tu Gbomedodoe.

In order to repeat the art music as in measures 3-16, I re-stated the 'second call' of the folk song in measures 17 and 18 (Figure 12). This enables me to use the technique of repetition as a means of extending the beginning section of Nyavs Nyee Tu Gbomedodoe in measures 19b-32. A third occurrence of the 'second call' (measures 33 and 34) leads the art-music into a bridge passage (Figure 13) and serves as a transition to a four-measure second theme in F major (Figure 14) as 'call-and-response' between the piano and the $\mathrm{B}^{\mathrm{b}}$ atcntebsn. The second theme is designed in 'call-and-response' form to depict the structure of the folk song; but its melody does not articulate the melodic structure of the folk song. This is a personal creativity technique to exemplify that the new music is a blend of Ghanaian traditional and western musical elements. 


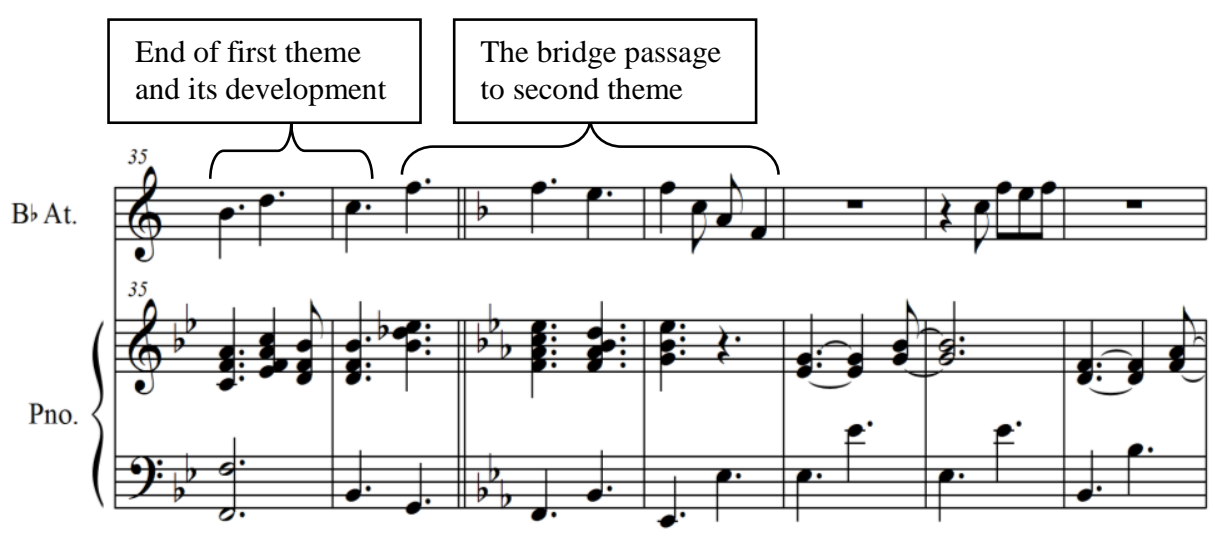

Figure 13. The bridge passage that serves as a transition to the second theme.

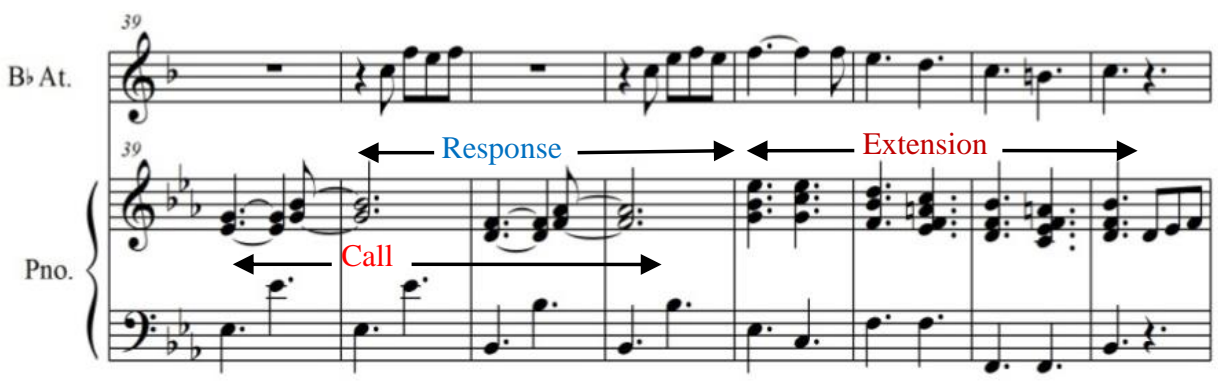

Figure 14. The second theme of the art-music Nyavs Nyee Tu Gbomedodoe as call and response between the piano and the $\mathrm{B}^{\mathrm{b}}$ atenteben.

The distinguishing feature of this second theme (as quoted above) is that, although the theme is written in the subdominant major it has returned to the tonic at the end. This is contrasting to the customary construction of the second theme in classical sonata form, most often in the dominant major (Kamien, 1998, p. 156; Kerman, 1980, p. 257).

In the classical sonata form, the development section of the music is characterised by manipulating the two themes as well as sub-themes created from the two main themes in varieties of keys (Kamien, 1998, pp. 156-157; Kerman, 1980 , p. 257). But in this music for the $\mathrm{B}^{\mathrm{b}}$ atenteben and piano, the development section is illustrated by a third set of musical design again in the subdominant major in measures 51 to 68 (Figure 15). 

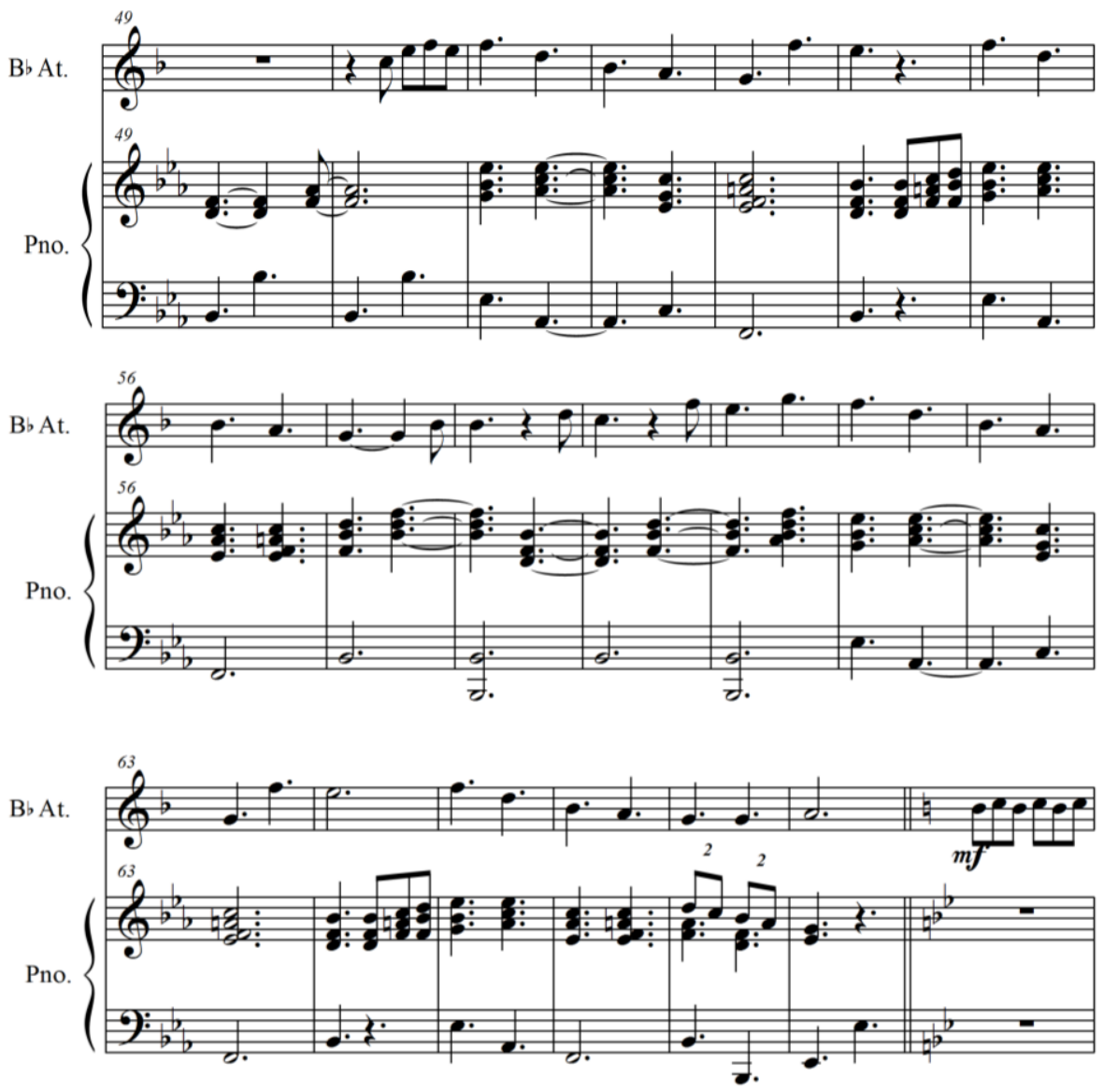

Figure 15. The third set of musical design that expresses the development section of the second theme in the art-music Nyavs Nyee Tu Gbomedodoe.

A return to the tonic, usually referred to as recapitulation is effected with a four-measure link from measure 69 to 72 as shown (Figure 16).

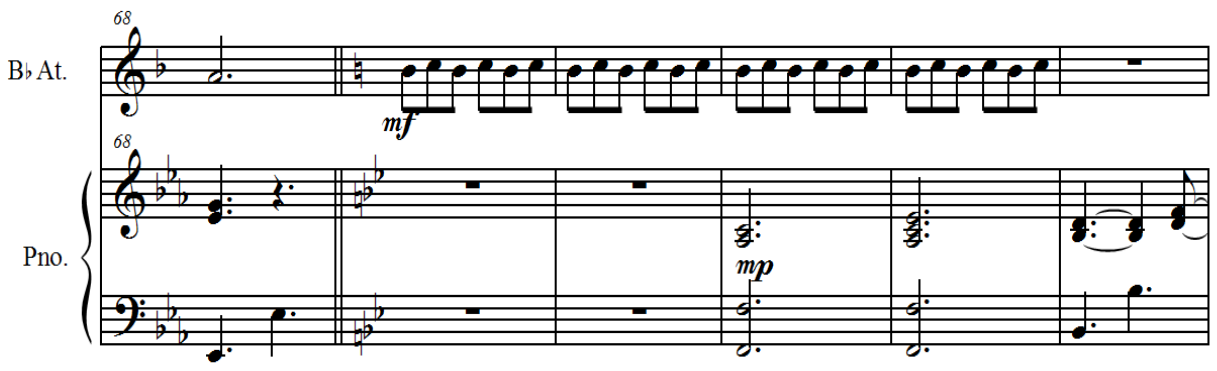

Figure 16. The second link that returns the music into the tonic. 
Additionally, in the classical sonata form, the recapitulation features both the first and second themes as well as other sub-themes of the music in the tonic (Kamien, 1998, p. 156; Kerman, 1980, p. 257). However, the recapitulation of Nyavs Nyee Tu Gbomedodoe, prominently exhibits the second theme and the new musical idea in measures 73 to 100 (Figure 17).
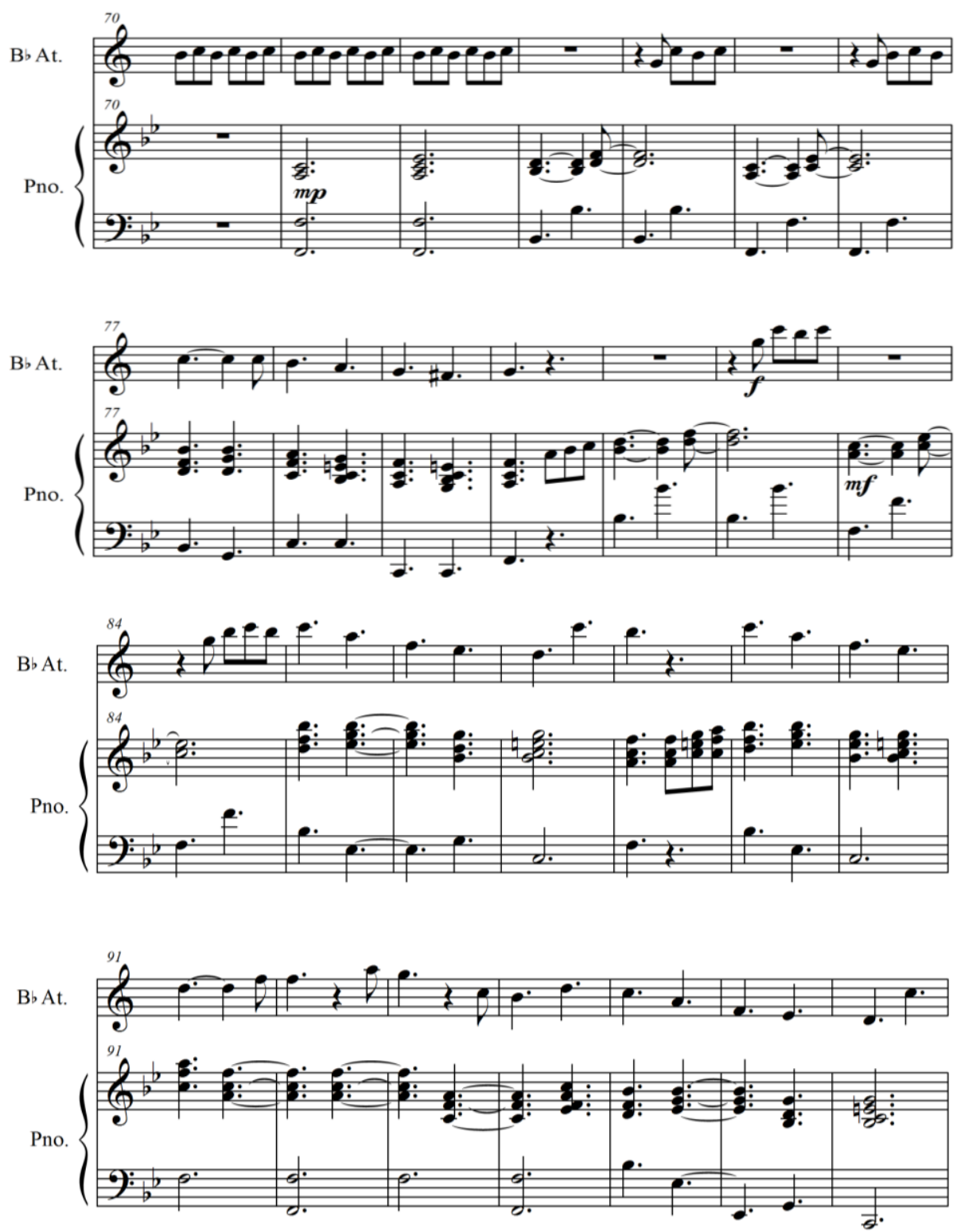

Figure 17. The second theme and the third musical idea of Nyavs Nyee Tu Gbomedodoe are re-written in the tonic and treated as the development section of the work. 
Through a very brief final bridge passage (measures 101-102 in Figure 18) the music finally ends with the restatement of the first theme and its extension as part of the recapitulation.

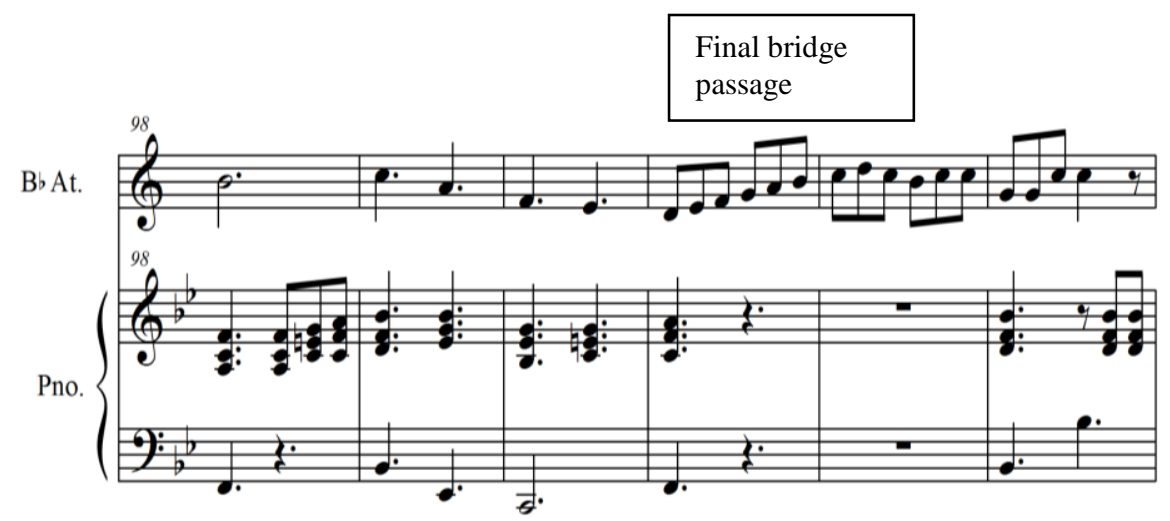

Figure 18. The final bridge passage in Nyavs Nyee Tu Gbomedodoe leading to the recapitulation.

\section{Conclusion}

The art music Nyavs Nyee Tu Gbomedodoe extracts a theme from a Ghanaian folk song and incorporates it into western classical style composition, expressing my identity as a crossbreed of Ghanaian traditional and British/Western musical cultures. The folk song also titled Nyavo Nyee Tu Gbomedodoe' has two sections. Each section has its 'call' and 'response', which, were used as the main theme, piano introduction, or an interlude. The rhythmic patterns of the sections were also integrated in the art music as supporting accompaniment in the piano or in the construction of the melodies of the new music. The tonal organisation of the folk song was also used to construct the melodies.

Utilising sonata form from European influence and the $\mathrm{B}^{\mathrm{b}}$ atcntebcn results in a type of 'Ghanaian Neoclassical' music: two disconnected 'classical' elements joined together for a new work. History discloses that the first people to research into African music were celebrated non-African ethnomusicologists including John Blackings, Simha Arom, Erich M. von Hornbostel, and A. M. Jones. To me, these researches marked the beginning of the globalisation/internationalisation of every kind of music performed by human societies. In Ghana, Ephraim Amu developed the traditional bamboo flute (atcntebcn) of the people of Kwahu to enhance its usage in playing Ghanaian as well as non-Ghanaian music. Traditional knowledge about the new instrument $\left(\mathrm{B}^{\mathrm{b}}\right.$ atcnteben) is that its music could only the written in the 'natural' mode because it is impossible to design the positions for Western chromatic notes on the instrument.

In this article, I have attempted to change the fashion of this knowledge that, through the development of alternative fingering techniques for the $\mathrm{B}^{\mathrm{b}}$ 
atcnteben (Adjahoe, 2016c, pp. 15-37), music for the instrument can be written in the following Western diatonic keys: $\mathrm{C}$ major, $\mathrm{F}$ major, $\mathrm{G}$ major by using my alternative fingering techniques. I have illustrated this with my composition entitled Nyavs Nyee Tu Gbomedodoe whose exposition travelled through the keys of $\mathrm{C}$ and $\mathrm{F}$ majors. The development section of the music reversed the approach; thus, it progressed through $\mathrm{F}$ major into $\mathrm{C}$ major. The recapitulation had a brief modulation into $\mathrm{G}$ major and finally re-established the music in $\mathrm{C}$ major. I have effectively performed the music using my fingering techniques in the video recording. Additionally, I have discovered that music for the $\mathrm{B}^{\mathrm{b}}$ atcnteben can be written in $\mathrm{A}$ minor and the Aeolian modes of C, F and G. My experimentation on the alternative fingering techniques in the production of chromatic notes is geared towards the internationalisation of the Ghanaian bamboo flute. This is my contribution towards the enhancement of the pedagogical processes involved in the teaching and learning of Ghanaian traditional musical instruments for performances in the world's concert halls.

\section{Acknowledgment}

This article was based on research developed from a paper presented and published as proceedings to the $2^{\text {nd }}$ International Music and Performing Arts Conference (IMPAC2016)(22-24 November 2016).

\section{References}

Adjahoe, M. Q. (1987). Atcnteben ensemble music. (Unpublished project work presented to the Department of Music, University of Cape Coast).

Adjahoe, M. Q. (2016a). New trends in $B^{b}$ atenteben music for colleges and universities. Cape Coast: University of Cape Coast Press.

Adjahoe, M. Q. (2016b). Anthology of $B^{b}$ atcntcben music for colleges and universities. Cape Coast: University of Cape Coast Press.

Adjahoe, M.Q. (2016c). From Ghanaian Folk Songs to Contemporary Art Music: The Style of Mawuyram Quessie Adjahoe. In Mohd Kipli Abdullah, Chan, C.S.C, Zaharul Lailiddin Saidon, Augustine, C. and Mumammad Fazli Taib Saearani (Eds). Proceedings of the $2^{\text {nd }}$ International Music and Performing Arts Conference (IMPAC2016)(22-24 November 2016), 198-225. Tanjong Malim: Universiti Pendidikan Sultan Idris

Agawu, V. K. (1984). The impact of language on musical composition in Ghana: An introduction to the musical style of Amu. Ethnomusicology 28 (1), 37-73.

Agawu, V. K (1987). The rhythmic structure of West African music. Journal of Musicology $5(3), 400-418$.

Agordoh, A. A. (2002). Studies in African music (Revised Edition). Sogakope: Comboni Printing School.

Agyemang, F. (1988). Amu the African. Accra, Asempa Publishers.

Apel, W. (2000). The Harvard dictionary of music. Cambridge, Ma: Belknap Press of Harvard University Press. 
Appiah, K. (2015, 7 March). To Nana Danso Abiam. Retrieved from https://www.graphic.com.gh/entertainment/music/to-nana-danso-abiam.html.

Craig, H. Artist biography. Retrieved from https://www.allmusic.com/artist/pan-africanorchestra-mn0001610789/biography

Flolu, J. \& Amuah, I. (2003). An introduction to music education in Ghana for universities and colleges. Accra. Primo Press.

Forney, K. \& Machlis, J. (2007). The enjoyment of music: An introduction to perceptive listening (Tenth edition). New York, NY: W.W. Norton and Company Inc.

Kamien, R. (1998). Music: An appreciation (Third edition). Boston, MA: McGraw-Hill.

Kerman, J. (1980). Listen (Third edition) New York, NY: Worth Publishers, Inc.

Nketia, J. H. K. (1974). The music of Africa. New York, NY: W.W. Norton and Company Inc.

Younge, P. Y. (2011). Music and dance traditions of Ghana: History, performance and teaching. London: McFarland \& Company, Inc., Publishers.

\section{Biography}

Adjahoe, Mawuyram Quessie is a senior lecturer in music theory and composition in the Department of Music \& Dance, University of Cape Coast, Cape Coast, Ghana, since September 2002. After his Bachelor of Music degree programme, he continued with the Master of Philosophy in Music Theory \& Composition, and Doctor of Philosophy in Music Composition all in the University of Cape Coast. He writes music for: $B^{b}$ atenteben and piano; $B^{b}$ atenteben ensembles, trios, and quartets; voice and piano; piano; and Gyile (Dagaaba traditional xylophone) Orchestra. From August 2012 to July 2014, he was appointed Head of the Department of Music and Dance in the University of Cape Coast. His publications include two articles written in 2009 and 2011 respectively; and three books which were completed in 2016. He has strong passion towards enhancing the pedagogical processes of Ghanaian traditional musical instruments. 